\title{
NATURAL PSYCHODYSLEPTIC COMPOUNDS: SOURCES AND PHARMACOLOGY
}

\author{
SISIRA PADAVALA, EZHILARASAN D*
}

Department of Pharmacology, Saveetha Dental College and Hospital, Chennai - 600 077, Tamil Nadu, India. Email: ezhild@gmail.com

Received: 08 June 2016, Revised and Accepted: 23 June 2016

\section{ABSTRACT}

Compounds in some plants have remarkable effects on the central nervous system. Plants containing those compounds are mind altering or psychoactive in nature. These are consumed in the form of simple or complex preparations to affect the mind or alter the state of consciousness. Psychoactivity may include sedative, stimulant, euphoric, deliriant, and hallucinogenic effects. Several hundred psychoactive plants are known. Some important examples of psychoactive plants include Datura, Salvia, and Cannabis. Psychoactive plants have been used ritually, medicinally, and recreationally for thousands of years. Hence, the sociocultural and economic significance of psychoactive plants is enormous.

Keywords: Cannabis, Datura, Psychoactive plants, Euphoria, Hallucinogen.

(C) 2016 The Authors. Published by Innovare Academic Sciences Pvt Ltd. This is an open access article under the CC BY license (http://creativecommons org/licenses/by/4. 0/) DOI: http://dx.doi.org/10.22159/ajpcr.2016.v9i5.13345

\section{INTRODUCTION}

Hallucinogenic plants have been used by man for thousands of years. Many species of hallucinogenic (psychodysleptic) plants are used by humans worldwide to achieve states of mind distortions; among those, a few have been used for therapeutic purposes such as Cannabis sativa L. and Banisteriopsis caapi. Certain compounds in these plants have remarkable effects on the central nervous system and are mind altering or psychoactive in nature [1]. These are consumed in the form of simple or complex preparations to affect the mind or alter the state of consciousness. These psychoactive plants contain hallucinogenic molecules that induce the production of altered states of consciousness. Psychoactivity may include sedative, stimulant, euphoric, deliriant, and hallucinogenic effects. Several psychoactive plants are identified so far, i.e., Datura, Salvia, Cannabis, etc. They have been used in many cultures throughout the centuries and have been consumed for their spiritual and religious purposes (Table 1). The main purpose for their use was to contact with spirits and for their psychoactive effects including euphoria. A few important psychoactive plants and their actions have been discussed in this article.

\section{Cannabis (C. sativa)}

Cannabis obtained from plant $C$. sativa also referred as Marijuana is the most commonly used illicit recreational drug worldwide. Cannabis is intoxicated through smoking. The psychoactive component of cannabis is $\Delta 9$ - tetrahydrocannabinol (THC) [1]. The three important forms of cannabis are marijuana, hashish, hash oil, and all of them contain THC as the psychoactive constitute [2]. THC in plasma is detectable which is fat soluble and stored in blood and is metabolized in the liver, accumulates in adipose tissue, released in urine after a long half-life of 7 days. The psychoactive effects start to appear immediately after use and are at the peak within half an hour $[2,3]$. Cannabis repeated injection can decrease the volume of gray matter of the medial temporal cortex, temporal pole, parahippocampal gyrus, left insula, and orbitofrontal cortex which are the motivational and affective components in brain The reduction in the gray matter volume is reported due to pruning of the synaptic connections. The decrease in hippocampal volume results in impaired activation during visual and verbal learning [4] The insulae are reported to be involved in the internal information, consciousness, emotion, decision making, error awareness, perception, motor control, self-awareness, and cognitive functioning [4]. Long-term use of cannabis results in aforesaid brain function alterations including impairment of working memory [1,4]. Cannabis has the ability to cause Paranoia. THC increases the occurrence of paranoia by an increase in the negative effect which consists of anxiety, worry, depression, negative thoughts about one's own self and also through, a range of confusing anomalous experiences [1]. The phytochemical constituents obtained from Cannabis show diverse biological effects in almost all organ systems especially cardiac, respiratory and immune system. Cannabinoid receptors (CB1 and CB2), THC are responsible for all the effects of cannabis.

The onset of actions varies depending on the duration, quantity, and age. In adolescents, the frequent use of cannabis in large quantities may trigger psychotic episodes or worsen the occurrence of psychosis in individuals already suffering from psychosis $[5,6]$. The chronic exposure in an adolescent female can cause depression, fatigue, anxiety, and low motivation probably due to self-medication of pre-existing depressive symptoms [6]. There is enough evidence that shows the alternations in the neurodevelopmental processes by the endocannabinoid system in the developing adolescent brain. This is probably said to involve the GABA and dopaminergic loss of function leading to a predisposition to develop schizophrenia [7]

Cannabis has significant effects on the impairment of basic cognitive functions due to THC intoxication from simple motor functions to complex executive functions such as making decisions, organizing, planning, problem solving and behavior in terms of speed, accuracy and latency [3]. Cannabis use impairs the working memory and delays task completion. This also promotes impulsive behavior which is unacceptable and maladaptive. There are no significant differences in terms of reasoning and attention $[3,8]$.

The derivatives of Cannabis can be used to treat nausea, anorexia and as an effective analgesic in low dose and a good pain reliever in medium dose $[9,10]$. Cannabis can be used as an anti-glaucoma agents to reduce the intraocular pressure, anti-asthmatic agents by bronchodilation, to treat convulsions, spasms, and difficulty of child labor [2]

\section{Fly agaric mushroom (Amanita muscaria)}

Red fly agaric mushroom is having hallucinogenic effect. Poisoning is extremely rare and accidentally occurs in children or due to overdose of the drug. It is consumed most commonly for suicidal or psychedelic effect [11]. A. muscaria contains poisonous alkaloids such as ibotenic acid, mucasone, muscimol, and muscarine. Among these ibotenic acid is a neurotoxin which activates the excitatory N-Methyl-D-Aspartate glutamate (NMDA) receptors. Ibotenic acid is similar in structure to glutamic acid and undergoes conversion by decarboxylation to muscimol. Fresh mushroom contains high ibotenic acid concentration, and hence, it is more toxic than dried one. Muscimol shows atropine-like 
Table 1: Some of psychodysleptic compounds and their sources and effects

\begin{tabular}{|c|c|c|c|c|}
\hline Source & Common name & Active compounds & Psychoactive effects & References \\
\hline Cannabis sativa & Cannabis & $\Delta 9$-tetrahydrocannabinol & $\begin{array}{l}\text { Influence on decisions, organizing, planning, } \\
\text { problem solving and behavior in terms of } \\
\text { speed, accuracy and latency. Paranoia and } \\
\text { predisposition to develop schizophrenia }\end{array}$ & {$[1,3,7]$} \\
\hline Amanita muscaria & $\begin{array}{l}\text { Fly agaric } \\
\text { mushroom }\end{array}$ & $\begin{array}{l}\text { Ibotenic acid, mucasone, } \\
\text { muscimol, muscarine }\end{array}$ & $\begin{array}{l}\text { Hallucinogenic effect, parasympathomimetic } \\
\text { action }\end{array}$ & {$[11]$} \\
\hline Psilocybe semilanceata & $\begin{array}{l}\text { Magic mushroom, } \\
\text { psilocybin } \\
\text { mushroom }\end{array}$ & Psilocybin & $\begin{array}{l}\text { Hallucinogenic effect, euphoria, visual } \\
\text { hallucination, dreamy state, alteration of body } \\
\text { image and time sense, amnesia, fear of death }\end{array}$ & {$[13,15,16]$} \\
\hline Banisteripsis caapi & Ayahuasca & $\begin{array}{l}\text { Harmine, tetrahydroharmine, } \\
\text { harmaline }\end{array}$ & $\begin{array}{l}\text { Well-being, antidepressant, anxiolytic, cognitive } \\
\text { and emotional modifications, euphoria }\end{array}$ & {$[18-21]$} \\
\hline Salvia divinorum & $\begin{array}{l}\text { Diviner's sage or } \\
\text { seer sage }\end{array}$ & $\begin{array}{l}\text { Salvinorin A, B, C, D, E and } \\
\text { divinatorin A, B, C }\end{array}$ & $\begin{array}{l}\text { Hallucinations, cartoon like images, } \\
\text { drowsiness, dissociative hallucination }\end{array}$ & {$[22-24,26]$} \\
\hline Datura stramonium & $\begin{array}{l}\text { Thorn apple, } \\
\text { jimson weed }\end{array}$ & $\begin{array}{l}\text { Atropine, scopolamine, } \\
\text { hyoscyamine }\end{array}$ & Hallucinations, confusion, ataxia & {$[28,29,31]$} \\
\hline
\end{tabular}

TCH: Tetrahydrocannabinol, Datura stramonium: D. stramonium, Salvia divinorum: S. divinorum, Banisteripsis caapi: B. caapi, Psilocybe semilanceata: P. semilanceata, Amanita muscaria: A. muscaria, Cannabis sativa: C. sativa

parasympatholytic action. It acts by blocking the GABA B receptor [11]. Muscarine has parasympathomimetic actions. Muscimol and ibotenic acid act as false neurotransmitters.

It has been demonstrated that muscarine chloride isolated from the A. muscaria shows significant effect on smooth muscles and glandular cells innervated by postganglionic cholinergic nerve fibers. This effect has been confirmed both in vivo and in vitro and came out with promising results such as spasm of uterus, gut, and urinary bladder, spasm of carotid artery and horse ureter, constriction of bronchi of Rabbit and Guinea pig, decrease in blood pressure and bronchoconstriction, miosis, uncoordinated abdominal, and thoracic movements [12].

Severe intoxication leads to respiratory and circulatory failure which subsequently cause coma and death. Mortality depends on the amount of poison absorbed. It is seen as fatal in $25 \%$ of cases [11]. Clinical manifestations of poisoning include weakness, confusion, dizziness, seizures, dilation of pupils, hyperemic conjunctiva, dry and redness of skin, increased salivary secretion, loss of response to voice and physical stimuli, hallucinations, spasms, flushing, increased body temperature. Diagnosis can be made by detecting the presence of ibotenic acid and muscimol in urine within $1 \mathrm{hr}$ of intoxication. Gastric lavage should be employed immediately as treatment. Atropine should not be given as antidote [11].

\section{Psilocybe semilanceata (Magic mushroom)}

Psilocybin is the primary hallucinogenic component of magic mushrooms. It is also a prodrug of psilocin, a mind manifesting psychedelic drug with a history of religious and recreational use [13,14]. It can stimulate existential experiences and is used in psychotherapy.

A study conducted to demonstrate the nuerometabolic effects of psilocybin found that there was hypermetabolism in prefrontal and temporal regions of the right hemisphere of brain and hypometabolism in the subcortical regions. Frontal cortical regions may be hyperactive in hallucinogenic states [15]. It causes other mental effects accompanied by sympathomimetic properties such as increase in blood pressure, pulse rate, body temperature, mydriasis, euphoria, visual hallucination, dreamy state, alteration of body image and time sense, feeling of strangeness and difficulty in thinking. Amnesia, paresthesia, fear of death and fear of harm to family are seen in most of the cases. Violence, convulsions, homicidal, and suicidal attempts are seen in few cases of poisoning [16]. It is also found to alter the blood vessels ability to respond to a stimulus resulting due to alterations in cerebrovascular reactivity [13].

Psilocybin can be used to treat cluster headaches. However, its inductive effects on headache are seen. It is activated through various mechanisms by (a) delayed headache induction through NO release (b) triggering of migraine through $5-\mathrm{HT}_{2 \mathrm{~B}}$ agonist (c) glutamate receptors activation may also lead to migraine [14]. Poisoning leads to attacks of tension, anxiety, palpitations, dryness of mouth, disturbed vision, depersonalization, bounding pulses, and suicidal feelings [17].

\section{B. caapi (Ayahuasca)}

Ayahuasca (AYA) obtained from psychotropic tea plant also called Daime or B. caapi contains beta-carboline alkaloids such as harmine, tetrahydroharmine, and harmaline [18]. $\beta$-carboline alkaloids inhibit monoamine oxidase $\mathrm{A}$ and serotonin uptake and have central $5-\mathrm{HT}_{1 \mathrm{~A}(2 \mathrm{~A}) 2 \mathrm{C}}$ (main excitatory receptor subtype among the $\mathrm{G}$ proteincoupled receptor for serotonin) agonist action on frontal and limbic areas. The combined action of these produces the psychoactive effects of AYA and causes a sensation of well-being, antidepressant and anxiolytic actions [18-20]. Ayahuasca increases the regional brain blood flow in frontal and paralimbic areas. It induces the activation of prefrontal and temporal regions in the brain. It produces intense cognitive, emotional, and perceptual modifications [21]. Oral administration of AYA induces euphoria, feeling of increased activation, well-being, somatic effects, changes in thought context, increased emotional liability and perceptual modifications [19].

\section{Salvia divinorum}

S. divinorum, also called Diviner's sage or seer sage, is a psychoactive plant referred to as "unregulated hallucinogen" or "illegal high" [22-24] It is used for recreational purposes. S. divinorum produces feelings of pressure on different parts of the body, unusual and revisiting childhood memories, contact with entities, cartoon-like imagery, changes in spatial orientation [25]. A "hangover" effect is noted after the peak effects subside including headache and drowsiness and synesthesia [24]. It produces dissociative, hallucinatory, and vision producing effects [26].

The important major component present in S. divinorum is salvinorin $A$, which is a non-nitrogenous diterpene responsible for hallucinogenic effects. Other minor diterpene compounds such as salvinorin $B$, salvinorin $C$, salvinorin $D$, salvinorin $E$, divinatorin $A$, divinatorin $B$, and divinatorin $\mathrm{C}$ also present insignificantly [22-27].

Interestingly, it has been reported that salvinorin A is a kappa opioid agonist which shows no activity at $5-\mathrm{HT}_{2 \mathrm{~A}}$ serotonin receptor which is the site of activation of other classic hallucinogens [25]. It is the most efficacious, naturally occurring kappa opioid and dopamine (D2) agonist $[23,26]$. The kappa opioid receptor (KOR) is a therapeutic target for analgesia [27] and has widespread distribution in the regions of the brain involved in reward, pain, interception, emotion and memory [22]. The psychomimetic effects of salvinorin A are similar to serotonergic agonists and NMDA receptor antagonists such as mescaline and lysergic 
acid diethylamide [26]. Stimulation of KOR results in diuresis, spinal analgesia, hallucinations, sedation, aversion, depression, and dysphoria. It has good anxiolytic effect and anti-depressive effect [24].

Salvinorin A ingestion orally does not produce hallucinogenic effects due to the first pass metabolism or enzyme deactivation. It is degraded by cytochrome oxidase isoenzymes such as CYP2D6, CYP1A1, CYP2C18, and CYP2E1 [24]. Inhalation of this drug causes hallucinations within seconds. The subjective effects of the drug are found to be different and unique from other hallucinogens [22]. Visual hallucinations and impairment of motor functions are seen within seconds [27].

\section{Datura stramonium}

D. stramonium is a medicinal as well as poisonous plant with psychoactive properties. It belongs to the family Solanaceae. It is also called "thornapple," "Jimson weed," Hells bell, Angels trumpet or Moon flower [28-32]. Datura has anticholinergic alkaloids such as atropine, scopolamine, and hyoscyamine, which are responsible for the actions of datura $[28,29,31]$. It was the for tropane alkaloids containing methylated nitrogen atom [29].

The ripe seeds and leaves of this plant contain a high concentration of toxic chemicals which are poisonous than any other part of the plant [31]. Poisoning leads to anticholinergic reactions. The tropane alkaloids act by competitively and irreversibly inhibiting acetyl chlorine on muscarinic receptors leading to central and peripheral nervous system effects. They can also show central and peripheral effects separately during poisoning. Toxicity results in convulsions and coma [31]. Death may occur due to poisoning or related causes like trauma. The patient may show symptoms such as flushing, mydriasis, dry skin, psychosis, seizures, respiratory failure, blurred vision, urinary retention, photophobia, ataxia, confusion, hallucinations, and hyperpyrexia [28]. The important challenge in datura poisoning is the delay in diagnosis [31]. The treatment is through gastric decontamination with activated charcoal in mouth [28]. Delirium and coma can be reversed by physostigmine salicylate [30].

D. stramonium is a potent bronchodilator mediated through inhibition of cholinergic airway smooth muscle tone [32]. Datura is used as alternative medicine to manage bronchitis, flu symptoms, and pain of childbirth, asthma [31]. It is also used to treat sinus infections, swellings, ulcers, and burns due to anti-inflammatory property. Used to treat alopecia, toothache, respiratory decongestion, pain of rheumatism, gout, headache, insomnia, Parkinsonism, hemorrhoids. The seeds are used as analgesic, antihelminthic, anti-inflammatory and for stomach pain. It also has antimicrobial activity and anti-cancer activity [29].

\section{CONCLUSION}

Psychoactive compounds obtained from plants or other sources show stimulatory effects even in low concentrations and may be fatal at higher doses. This review throws light on understanding of the effects of the psychoactive plants may act as an aid to identify and treat the poisoning with the psychoactive drugs and their derivatives at the time of need and save lives by preventing the adverse effects and further progression of the severe harmful effects.

\section{REFERENCES}

1. Freeman D, Dunn G, Murray RM, Evans N, Lister R, Antley A, et al. How cannabis causes paranoia: Using the intravenous administration of $\Delta 9$-tetrahydrocannabinol (THC) to identify key cognitive mechanisms leading to paranoia. Schizophr Bull 2015;41(2):391-9.

2. Cho CM, Hirsch R, Johnstone S. General and oral health implications of cannabis use. Aust Dent J 2005;50(2):70-4.

3. Crean RD, Crane NA, Mason BJ. An evidence based review of acute and long-term effects of cannabis use on executive cognitive functions. J Addict Med 2011;5(1):1-8.

4. Battistella G, Fornari E, Annoni JM, Chtioui H, Dao K, Fabritius $\mathrm{M}$, et al. Long-term effects of cannabis on brain structure. Neuropsychopharmacology 2014;39(9):2041-8.
5. Henquet C, Krabbendam L, Spauwen J, Kaplan C, Lieb R, Wittchen $\mathrm{HU}$, et al. Prospective cohort study of cannabis use, predisposition for psychosis, and psychotic symptoms in young people. BMJ 2005;330(7481):11.

6. Patton GC, Coffey C, Carlin JB, Degenhardt L, Lynskey M, Hall W. Cannabis use and mental health in young people: Cohort study. BMJ 2002;325(7374):1195-8.

7. Malone DT, Hill MN, Rubino T. Adolescent cannabis use and psychosis: Epidemiology and neurodevelopmental models. Br J Pharmacol 2010;160(3):511-22.

8. Hart CL, van Gorp W, Haney M, Foltin RW, Fischman MW. Effects of acute smoked marijuana on complex cognitive performance. Neuropsychopharmacology 2001;25(5):757-65.

9. Jouanjus E, Lapeyre-Mestre M, Micallef J; French Association of the Regional Abuse and Dependence monitoring centres (CEIP-A) working group on cannabis complications*. cannabis use: Signal of increasing risk of serious cardiovascular disorders. J Am Heart Assoc 2014;3(2):e000638.

10. Wilsey B, Marcotte T, Deutsch R, Gouaux B, Sakai S, Donaghe H. Low-dose vaporized cannabis significantly improves neuropathic pain. J Pain 2013;14(2):136-48

11. Mikaszewska-Sokolewicz MA, Pankowska S, Janiak M, Pruszczyk P, Lazowski T, Jankowski K. Coma in the course of severe poisoning after consumption of red fly agaric (Amanita muscaria). Acta Biochim Pol 2016;63(1):181-2.

12. Fraser PJ. Pharmacological actions of pure muscarine chloride. Br J Pharmacol Chemother 1957;12(1):47-52.

13. Carhart-Harris RL, Erritzoe D, Williams T, Stone JM, Reed LJ, Colasanti A, et al. Neural correlates of the psychedelic state as determined by fMRI studies with psilocybin. Proc Natl Acad Sci U S A 2012;109(6):2138-43.

14. Johnson MW, Sewell RA, Griffiths RR. Psilocybin dose-dependently causes delayed, transient headaches in healthy volunteers. Drug Alcohol Depend 2012;123(1-3):132-40.

15. Gouzoulis-Mayfrank E, Schreckenberger M, Sabri O, Arning C, Thelen B, Spitzer M, et al. Neurometabolic effects of psilocybin, 3,4-methylenedioxyethylamphetamine (MDE) and d-methamphetamine in healthy volunteers. A double-blind, placebo-controlled PET study with [18F]FDG. Neuropsychopharmacology 1999;20(6):565-81.

16. Musha M, Ishii A, Tanaka F, Kusano G. Poisoning by hallucinogenic mushroom hikageshibiretake (Psilocybe argentipes K. Yokoyama) indigenous to Japan. Tohoku J Exp Med 1986;148(1):73-8.

17. Benjamin C. Persistent psychiatric symptoms after eating psilocybin mushrooms. Br Med J 1979;1(6174):1319-20.

18. Osório Fde L, Sanches RF, Macedo LR, Santos RG, Maia-deOliveira JP, Wichert-Ana L, et al. Antidepressant effects of a single dose of ayahuasca in patients with recurrent depression: A preliminary report. Rev Bras Psiquiatr 2015;37(1):13-20.

19. Riba J, Valle M, Urbano G, Yritia M, Morte A, Barbanoj MJ. Human pharmacology of ayahuasca: Subjective and cardiovascular effects, monoamine metabolite excretion, and pharmacokinetics. J Pharmacol Exp Ther 2003;306(1):73-83.

20. Riba J, Anderer P, Morte A, Urbano G, Jané F, Saletu B, et al. Topographic pharmaco-EEG mapping of the effects of the South American psychoactive beverage ayahuasca in healthy volunteers. $\mathrm{Br}$ J Clin Pharmacol 2002;53(6):613-28.

21. Bouso JC, González D, Fondevila S, Cutchet M, Fernández X, Ribeiro Barbosa PC, et al. Personality, psychopathology, life attitudes and neuropsychological performance among ritual users of Ayahuasca: A longitudinal study. PLoS One 2012;7(8):e42421.

22. MacLean KA, Johnson MW, Reissig CJ, Prisinzano TE, Griffiths RR. Dose-related effects of salvinorin A in humans: Dissociative, hallucinogenic, and memory effects. Psychopharmacology (Berl) 2013;226(2):381-92.

23. Listos J, Merska A, Fidecka S. Pharmacological activity of salvinorin $\mathrm{A}$, the major component of Salvia divinorum. Pharmacol Rep 2011;63(6):1305-9.

24. Rosenbaum CD, Carreiro SP, Babu KM. Here today, gone tomorrow and back again? A review of herbal marijuana alternatives (K2, Spice), synthetic cathinones (bath salts), kratom, Salvia divinorum, methoxetamine, and piperazines. J Med Toxicol 2012;8(1):15-32.

25. Johnson MW, MacLean KA, Reissig CJ, Prisinzano TE, Griffiths RR. Human psychopharmacology and dose-effects of Salvinorin A, a kappa opioid agonist hallucinogen present in the plant Salvia divinorum. Drug Alcohol Depend 2011;115(1-2):150-5.

26. Winslow M, Mahendran R. From divination to madness: Features of acute intoxication with Salvia use. Singapore Med J 2014;55(4):e52-3. 
27. Hooker JM, Xu Y, Schiffer W, Shea C, Carter P, Fowler JS Pharmacokinetics of the potent hallucinogen, Salvinorin A in primates parallels the rapid onset and short duration of effects in humans. Neuroimage 2008;41(3):1044-50.

28. Kurzbaum A, Simsolo C, Kvasha L, Blum A. Toxic delirium due to Datura stramonium. Isr Med Assoc J 2001;3(7):538-9.

29. Soni P, Siddiqui AA, Dwivedi J, Soni V. Pharmacological properties of Datura stramonium L. as a potential medicinal tree: An overview.
Asian Pac J Trop Biomed 2012;2(12):1002-8.

30. Belton PA, Gibbons DO. Datura intoxication in West Cornwall. Br Med J 1979;1(6163):585-6.

31. Adegoke SA, Alo LA. Datura stramonium poisoning in children. Niger J Clin Pract 2013;16(1):116-8.

32. Charpin D, Orehek J, Velardocchio JM. Bronchodilator effects of antiasthmatic cigarette smoke (Datura stramonium). Thorax 1979;34(2):259-61. 